\title{
Anaerobic microorganisms in root canals of human teeth with chronic apical periodontitis detected by indirect immunofluorescence
}

Assed S, Ito IY, Leonardo MR, Silva LAB, Lopatin DE. Anacrobic microorganisms in root canals of human tecth with chronic apical periodontitis detected by indirect immunofluorescence. Endod Dent Traumatol 1996; 12: 6669. (C) Munksgaard, 1996.

Abstract Aiming to assess the presence of selected anacrobic microorganisms in root canals of human tecth with chronic apical periodontitis, 25 central and lateral upper incisors presenting with radiographic evidence of chronic apical periodontitis were studied. The pulp chamber was opened under aseptic conditions and samples of the root canal content were collected with sterile absorbent paper points, which were placed and dispersed in test tubes containing redueed transport medium (RTF). Aliquots were dried on glass slides and stained by indirect immunofluorescence for detection of Actinomyces viscosus, Fusobacterium nucleatum, Porphoromonas gingizalis and Prevolella intermedia. The results showed a positive indirect immunofluorescence reaction in 24 of the 25 samples. Fourtecn were positive for the specie Actinomyces viscosus, 12 for Prevolella intermedia, 10 for Fusobacterium nucleatum and 4 for Porplyromonas gingivalis. A semiquantitative assay was easily implemented for assessment of degree of infection by the organisms in individual cases.
S. Assed ${ }^{1}$, I.Y. Ito ${ }^{2}$, M.R. Leonardo ${ }^{3}$, L.A.B. Silva ${ }^{1}$, D.E. Lopatin ${ }^{4}$

Departments of ${ }^{1}$ Pediatric Dentistry, ${ }^{2}$ Health Sciences, Ribeirão Preto School of Pharmacy, USP, ${ }^{3}$ Endodontics, Araraquara School of Dentistry, UNESP, ${ }^{4}$ Biologic and Materials Sciences, School of Dentistry, University of Michigan, Ann Arbor, USA

Key words: apical periodontitis; indirect immunofluorescence; anaerobic microorganisms M. R. Leonardo, Department of Endodontics, Faculdade de Odontologia de Araraquara, UNESP. P.O. Box 331, 14801-385, Araraquara, SP, Brazil. Accepted May 13, 1995
The important role of the bacteria in the pathogenesis of the pulpal and periapical disease has been extensively demonstrated (1-4), and the microorganisms present in the root canal can survive and maintain a periapical infectious process (5). Therefore, one of the prime objectives of endodontic treatment is the elimination of infection from the root canal system and the prevention of a reinfection $(6,7)$.

Until the 1970s the most commonly identified bacteria in infected root canals were the acrobes and the facultative anaerobes. When strictly anacrobic culture techniques are used, it has been shown that, the microorganisms which predominated in the infected root canal system of teeth with chronic apical periodontitis are anacrobes.

Besides the culture techniques, immunocytochemical methods demonstrate the presence of anacrobic microorganisms. Particularly, indirect immunofluorescence is a rapid method which may be used to detect live and dead microorganisms $(8-10)$.

Thus, our aim was to assess the presence of Actinomves viscosus, Prevolella intermedia, Fusobacterium mudeatum and Porphromonas gingizalis in human tecth with chronic apical periodontitis using the indirect immunofluorescence technique in material sampled before the biomechanical preparation.

\section{Material and methods}

Twenty-five upper lateral and central incisor teeth with caries lesions, pulp necrosis, and radiographically demonstrable, chronic apical periodontitis were selected from 23 adult 20- to 30-ycar-old patients. 
After isolation with a rubber dam the operative field was disinfected with $0.3 \%$ iodoethanol.

When coronary access and pulp chamber irrigation with sterile physiological saline had been performed, the sampling for the bacteriological examination was effected. Sterile paper points were introduced for approximately one minute in the root canal, in increasing sizes from 15 to 30 . The paper points were removed and placed in a $13 \times 100 \mathrm{~mm}$ test tube containing $2 \mathrm{ml}$ of reduced transport fluid (R'TF), prepared according to Syed \& Loesche (11). In this sampling as many paper points as necessary were utilized successively until an apparently dry paper point could be drawn from the root canal (3 to 4 paper points). Subsequent treatment procedures were performed according to conventional methods using chemomechanical preparation and antibacterial dressing with calcium hydroxide paste, and the root canal were filled using the lateral condensation technique with gutta-percha points and root canal sealer (Sealapex, Sybron-Kerr, São Paulo, Brazil).

\section{Indirect immunofluorescence}

Sterile barbed wings were placed inside the test tubes containing the samples and stirring in a shaker (Mixtron-Toptronix) was done in order to effect the desorption of the microorganisms from the paper points.

Indirect immunofluorescence assays were performed according to Van Poperin \& Lopatin (12) and Zambon et al. (13). Briefly, a $10 \mu$ aliquot of each sample was placed in one of the well of special glass slides (Lioserum, SP, BZ) for the immunological reaction. In one of the wells, $10 \mu \mathrm{l}$ of an Escherichia coli suspension were applied for a negative control and a pooled suspension containg Actinomyces viscosus, Fusobacterium mucleatum, Prevotella intermedia and Porphyromonas gingivalis (provided by D. E. Lopatin, University of Michigan School of Dentistry, Ann Harbor, Michigan, USA) was applied to another well as a positive control.

After drying at room temperature, the glass slides were submitted to gentle flame fixation. Ten $\mu$ of the specific antibodies: anti-Actinomyces viscosus, Fusobacterium mucleatum, Prevotella intermedia or Porphyromonas gingivalis (also provided by D. E. Lopatin) appropriately diluted in phosphate buffered saline solution, $\mathrm{pH} 7.2$ $0.15 \mathrm{M}$ with $2.0 \%$ bovine albumin serum-AB (PBS2.0-AB) were applied and incubated during $10 \mathrm{~min}-$ utes at $37^{\circ} \mathrm{C}$ in a humid chamber. After incubation, the glass slides were washed with phosphate buffered saline containing $0.05 \%$ Tween 20 (PBS-T) for 10 minutes, then washed with distilled water and dried at room temperature. Afterwards, $10 \mu \mathrm{l}$ of fluoresceinconjugated, goat anti-rabbit gammaglobulin (Sigma F9887) diluted in PBS-2.0-AB were applied to each of the wells and incubated during 10 minutes at $37^{\circ} \mathrm{C}$ in a wet chamber, then washed as described above. After drying, the glass slides were mounted with 0.05 $\mathrm{ml}$ buffered glycerol-PBS (2:1, v/v, pH 9.0) with $0.05 \%$ Trypan bluc (Merck), covered with coverglasses fixed with nail varnish, placed in a humid chamber and analyzed within two hours in a fluorescence microscope JENAMED 2, Carl Zeiss, GF PW 10x, Planachromat HI $100 \times$.

The samples were examined for the presence of fluorescent cells. A total of 100 bacterial cells, or the whole smear, were counted in each well.

The results were registered as number of + signs: ++++ , when more than 10 cells were present in most of the fields; +++ , when 5-10 were observed in most of the fields; ++ from 1 to 4 and + , when up to 10 cells were observed all over the smear. The number of + signs was considered "infection grade" of "infection intensity".

\section{Results}

Table 1 shows the presence of four species of bacteria (Actinomyces viscosus, Prevotella intermedia, Fusobacterium nucleatum and Porphyromonas gingivalis) in the sampled root

Table 1. Presence of species of anaerobes ( $A$. viscosus, P. intermedia, F. nucleatum and $P$. gingivalis) and grade of infection in the samples collected in root canals before biomechanics (immunofluorescence technique)

\begin{tabular}{|c|c|c|c|c|}
\hline \multirow[b]{2}{*}{ Cases } & \multicolumn{4}{|c|}{ Species of anaerobes } \\
\hline & A. viscosus & P. intermedia & F. nucleatum & $P$. gingivalis \\
\hline P1 & $+t+t$ & $++t+$ & - & - \\
\hline P2 & - & - & + & - \\
\hline P3 & + & +++ & - & - \\
\hline P4 & + & - & $+t+t$ & - \\
\hline P5 & $+++t$ & + & - & - \\
\hline P6 & + & - & - & - \\
\hline P7 & & - & $+t$ & - \\
\hline P8 & $+t+t$ & - & $++t+$ & - \\
\hline P9 & + & + & - & + \\
\hline P10 & - & - & + & - \\
\hline P11 & ++++ & ++ & + & - \\
\hline P12 & - & - & $+t$ & - \\
\hline P13 & + & + & ++ & - \\
\hline P14 & - & - & - & + \\
\hline P15 & - & + & - & - \\
\hline P16 & + & ++ & - & - \\
\hline P17 & - & - & - & - \\
\hline P18 & + & - & - & + \\
\hline P19 & - & - & +++ & - \\
\hline P20 & - & - & - & + \\
\hline P21 & + & + & - & - \\
\hline P22 & + & $+t+t$ & - & - \\
\hline P23 & & $++t+$ & - & - \\
\hline P24 & - & $+t+t$ & $+++t$ & - \\
\hline P25 & + & - & - & - \\
\hline
\end{tabular}

The number of signs indicates the intensity of the infection: ++++ (more than 10 cells in most of the fields examined), +++ (from 5 to 10 cells in most of the fields), ++ (from 1 to 4 cells in most of the fields), + (up to 10 cells all over the smear), - (non-detected bacterium). 


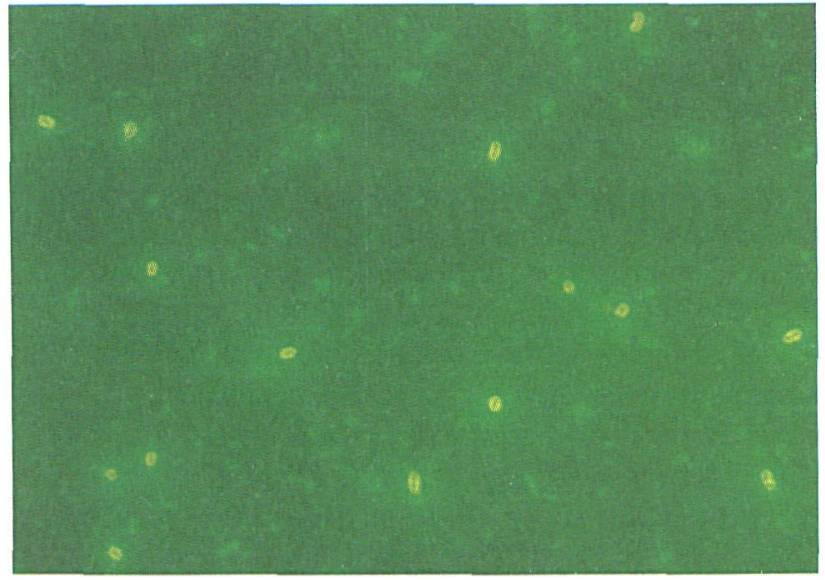

Fig. 1. Indirect immunofluorescence showing Prevolella intermedia (case \#24).

canals. Twenty-four samples were positive for at least one of the searched species: 11 samples showed only one species of anaerobes; and 13 samples harbored more than one species of the latter 10 harbored two species and 3 harbored three species. In none of the 24 positive samples the simultanous presence of the four investigated species was observed.

For every species of bacteria the intensity of the infection varied among the samples, with the exception of Porphyromonas gingivalis which showed only a grade 1 positive immunofluorescence reaction.

\section{Discussion}

Using the indirect immunofluorescence technique in the material sampled in 25 root canals before biomechanical preparation, the specie Actinomyces viscosus was detected in $56 \%$ of cases. This result is similar to the $60.0 \%$ observed by Gohean et al. (10) in samples collected in root canals of teeth with periapical lesions submitted to the indirect immunofluorescence reaction. The presence of Actinomyces was also demonstrated by Borssén \& Sundqvist (14) using the indirect immunofluorescence in $25(10.6 \%)$ strains of the 235 positive cultures.

Actinomyces has a known pathogenic potential $(9,14$, 15). It may survive in the periapical tissue and may jeopardize the normal process of repair and may be the cause of periapical lesions resistant to the endodontic treatment $(5,7,16)$.

The prevalence of Prevotella intermedia $(48.0 \%)$ observed in this study agreed with the observations of Pantera Jr. et al. (8), who detected B. intermedius (Prevotella intermedia) in $43.0 \%$ of the root canal samples tested with indirect immunofluorescence. The presence of $B$. intermedius (Prevotella intermedia) was also ob- served by immunofluorescence in the periapical granuloma by Barnett et al. (9).

Also, the prevalence of Porphyromonas gingivalis detected in this study in $16.0 \%$ of the cases was similar to the observed by Pantera Jr. et al. (8) who detected B. gingivalis (Porphyromonas gingivalis) in $15.0 \%$ of the samples from human teeth with periapical lesions.

The Fusobacterium nucleatum prevalence of $40.0 \%$ cannot be directly compared to other findings as there are no other studies using indirect immunofluorescence to detect this microorganism. However, Byström \& Sundqvist (17), Wayman et al. (18) and Sundqvist (15), among many others have reported the isolation of Fusobacterium nucleatum in root canals of human teeth with necrotic pulp.

In a comparison of the anacrobic culture method with the indirect immunofluorescence reaction, Pantera Jr. et al. (8) showed the presence of Bacteroides species in $27.0 \%$ of the bacteriological samples from extracted teeth and in $20.0 \%$ taken from patients, while using the indirect immunofluorescence technique species Bacteroides were detected in 86.0 and $40.9 \%$ of the same samples, respectively. Bacteroides intermedius (Prevotella intermedia) was observed, by the culture method, in only $11.0 \%$ of the samples collected in patients; however, it was identified in $43.0 \%$ of these samples by the indirect immunofluorescence reaction. Bacteroides gingivalis (Porphyromonas gingizalis) isolated in $4.0 \%$ of the samples from patients through indirect immunofluorescence was found in $15.0 \%$ of these samples. More recently, Yi et al. (19) used the culture technique and the indirect immunofluorescence with monoclonal antibody to detect $P$. endodontalis in 24 samples of pus from root canals of teeth with periapical abscess. They observed that the culture was positive in $25 \%$ of the cases, while indirect immunofluorescence was positive in $37.5 \%$. Thus, they concluded that the immunofluorescence technique is less time-consuming and more sensitive to detect $P$. endodontalis, dispensing the bacterial culture.

These data demonstrated the importance of the indirect immunofluorescence reaction when compared to the microbiological culture method.

The value of the indirect immunofluorescence reaction was also reported by Loesche et al. (20), when the anaerobic culture technique, the DNA probing, the ELISA reaction and the indirect immunofluorescence were compared in the detection of periodontopathogenic microorganisms.

For indirect immunofluorescence assay it is important the use of a adequate dilution of antisera, both bacteria specific as well as fluosrescein-conjugate gammaglobulin. The use-dilution of cach antibody were determined by the "block titletion" technique as proposed by Bier (21).

Our results allowed us to confirm that the indirect immunofluorescence was an effective, quick and prac- 
tical method to detect anaerobic microorganisms in root canals.

\section{References}

1. Kakehashi S, Stanley HR, Fitzegerald RJ. The effects of surgical exposure of dental pulps in germ-free and conventional laboratory rats. Oral Surg Oral Med Oral Pathol 1965; 20: 340 9.

2. Möller AJr, Fabrteius l, Dahlén G, Ohman A, Heiden G. Influence on periapical tissues of indigenous oral bacteria and necrotic pulp tissuc in monkeys. Scand 7 Dent Res 1981; 89: $475-84$.

3. Fabricius L, Dahlén G, Öhman AE, Möller JR. Predominant indigenous oral bacteria isolated from infected root canals after varied times of closure. Scand J Dent Res 1982; 90: 134 44.

4. Paterson RC, Watts A. Further studies on the exposed germfree dental pulp. Int Endod J 1987; 20: 11221.

5. Tronstad L, Barnett F, Riso K, Slots J. Extraradicular endodontic infections. Endod Dent Traumatol 1987; 3: 86-90.

6. Leonardo MR. Fase da desinfeçäo do sistema da canal radicular. Consideraçöes iniciais, agentes antimicrobanos. In: Leonardo MR, Leal JM. Endodontia: Tratamento de canais radiculares. 2" ed., São Paulo, Brasil: Médica Panamericana; 1991.

7. Byström A, Happonen RP, Sjögren U, Sundevist G. Healing of periapical lesions of pulpless teeth after endodontic treatment with controlled asepsis. Endod Dent Traumatol 1987; 3: 5863.

8. Pantera Jr E A, Zambon JJ, Levine MS. Indirect immunofluorescence for the detection of Bacteroides species in human dental pulp. 7 Endod 1988; 14: $218-23$.

9. Barnett F, Stevens R, Tronstad L. Demonstration of Bacter- oides intermedius in periapical tissue using indirect immunofluorescence microscopy. Endod Dent Traumatol 1990; 6: 153-6.

10. Gohean RJ, Pantera Jr EA, Schuster GS. Indirect immunofluorescence microscopy for the identification of Antinomyces sp. in endodontic discase. 7 Endod 1990; 16: 318-22.

11. Syed SA, Loesche WJ. Survival of human dental plaque flora in various transport media. Appl Microbiol 1972; 24: 638-44.

12. Van Poperin N, Lopatin DE. Slot immunoblot assay for detection and quantification of periodontal discase - associated microorganisms in dental plaque. I Clin Microbiol 1991; 29: $2554-8$.

13. Zambon .JJ, Reynolds HS, Chen P, Genco RJ. Rapid identificatin of periodontal pathogens in subgingival dental plaque. J Periodontol 1995; 56: 32-40 (sp issue).

14. Borssén E, Sundevist G. Actinomyces of infected dental root canals. Oral Surg Oral Med Oral Pathol 1981; 51: 643-8.

15. Sundevist G. Associations between microbial species in dental root canal infections. Oral Microbiol Immunol 1992; 7: 257-62.

16. Happonen RP. Periapical actinomycosis: A follow-up study of 16 surgically treated cases. Endod Dent Traumatol 1986; 2: 2059.

17. Byström A, Sundevist G. Bacteriologic evaluation of the effect of 0.5 percent sodium hypochlorite in endodontic therapy. Oral Surg Oral Med Oral Pathol 1983; 55: 307-12.

18. Wayman BE, Murata SM, Almeida RJ, Fowler CB. A bacteriological and histological evaluation of 58 periapical lesions. 7 Endod 1992; 18: 152-5.

19. Yi X, Julian T, Chao'an S, Bin L, Tahe J, Jun-Nan S. Rapid identification of Porphyromonas endodontalis in periapical abscesses by monoclonal antibody. Endod Dent Traumatol 1994; 10: 54.

20. Loesche WJ, Lopatin DE, Stoll J, van Poperin N, Hujoel P. Comparison of various detection methods for periodontopathic bacteria: can culture be considered the primary reference standard? f Clin Microbiol 1992; 30: 418-26.

21. Bier O. Microbiologia e imunologia. $24^{\mathrm{a}} \mathrm{ed}$. São Paulo, Melhoramentos, 1985. 
This document is a scanned copy of a printed document. No warranty is given about the accuracy of the copy. Users should refer to the original published version of the material. 